\title{
PEMBUATAN DAN KARAKTERISASI SIFAT FISIS ELEKTRODA KARBON DARI BUNGA RUMPUT GAJAH DITINJAU DARI PERBEDAAN UKURAN PARTIKEL
}

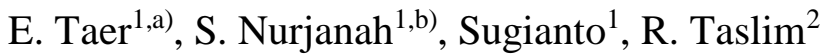 \\ ${ }^{1}$ Jurusan Fisika, Universitas Riau, Simpang baru, Pekanbaru, 28293 \\ ${ }^{2}$ Jurusan Teknik Industri, Universitas Islam Negeri Sultan Syarif Kasim, Pekanbaru, 28293

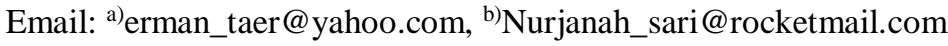

\begin{abstract}
Abstrak
Pembuatan dan karakterisasi sifat fisis elektroda karbon dari bunga rumput gajah telah dianalisis dengan memvariasikan ukuran partikel. Pembuatan elektroda karbon dimulai dengan pra-karbonisasi, penggilingan dengan hard grinder, penggilingan dengan ball milling dan diikuti dengan proses pengayakan. Variasi ukuran partikel yang dipilih $<38 \mu \mathrm{m}$ dilanjutkan penggilingan selama 20 jam (SA), $<38 \mu \mathrm{m}$ (SB), dan 39-52 $\mu \mathrm{m}$ (SC). Semua sampel diaktivasi kimia dengan aktivator $\mathrm{NaOH}$ pada konsentrasi $0,4 \mathrm{M}$. Proses karbonisasi dilakukan pada suhu $600^{\circ} \mathrm{C}$ dalam lingkungan gas $\mathrm{N}_{2}$ dan dilanjutkan dengan proses aktivasi fisika dengan menggunakan gas $\mathrm{CO}_{2}$ pada suhu $850^{\circ} \mathrm{C}$. Parameter fisis seperti massa, diameter dan ketebalan elektroda karbon aktif dikumpulkan pada suatu kondisi (i) sebelum karbonisasi, (ii) setelah karbonisasi dan (iii) setelah aktivasi fisika yang bertujuan untuk mendapatkan besaran densitas. Hasil data densitas masing-masing menunjukkan bahwa sampel SA (i) memiliki nilai densitas sebesar $1,103 \mathrm{~g} / \mathrm{cm}^{3}$, (ii) $0,869 \mathrm{~g} / \mathrm{cm}^{3}$, (iii) $0,800 \mathrm{~g} / \mathrm{cm}^{3}$, $\mathrm{SB}$ (i) $1,083 \mathrm{~g} / \mathrm{cm}^{3}$, (ii) $0,816 \mathrm{~g} / \mathrm{cm}^{3}$, (iii) $0,728 \mathrm{~g} / \mathrm{cm}^{3}$ dan $\mathrm{SC}$ (i) $1,072 \mathrm{~g} / \mathrm{cm}^{3}$, (ii) $0,777 \mathrm{~g} / \mathrm{cm}^{3}$ dan (iii) $0,599 \mathrm{~g} / \mathrm{cm}^{3}$. Sehingga dapat disimpulkan, ukuran partikel berbanding terbalik dengan densitas. Sebagai tambahan, analisis kristalografi menunjukkan bahwa ukuran partikel berbanding terbalik dengan nilai Lc.
\end{abstract}

Kata kunci : ukuran partikel, sifat fisis, karbon aktif, bunga rumput gajah

\begin{abstract}
Preparation and characterization of physical properties of carbon electrode from flower of elephant grass has been analyzed with variations in particle size. Production of carbon electrodes was begun with precarbonization, grinding with hard grinder, grinding with ball milling and followed by sieving process. Variations in particle size selected of $<38 \mu \mathrm{m}$ milling continued during 20 hours, $<38 \mu \mathrm{m}$ (SB), and 39-52 $\mu \mathrm{m}$ (SC). All of the sample have been activated by chemical activating agent with $\mathrm{NaOH}$ at a concentration of $0,4 \mathrm{M}$. Carbonization process was performed at temperatures of $600^{\circ} \mathrm{C}$ in the gas environment $\mathrm{N}_{2}$ and followed by physical activation process by using a $\mathrm{CO}_{2}$ gas at a temperature of $850^{\circ} \mathrm{C}$. Physical parameters such as mass, diameter and thickness of activated carbon electrodes was collected at a condition (i) before carbonization, (ii) after carbonization and (iii) after physical activation to found the density characteristic. The results of density data showed that the sample SA of $<38 \mu \mathrm{m}$ has a density value of $1,103 \mathrm{~g} / \mathrm{cm}^{3}$, (ii) $0,869 \mathrm{~g} / \mathrm{cm}^{3}$, (iii) $0,800 \mathrm{~g} / \mathrm{cm}^{3}, \mathrm{SB}$ (i) $1,083 \mathrm{~g} / \mathrm{cm}^{3}$, (ii) $0,816 \mathrm{~g} / \mathrm{cm}^{3}$, (iii) $0,728 \mathrm{~g} / \mathrm{cm}^{3}$ and SC (i) $1,072 \mathrm{~g} / \mathrm{cm}^{3}$, (ii) $0,777 \mathrm{~g} / \mathrm{cm}^{3}$ and (iii) $0,599 \mathrm{~g} / \mathrm{cm}^{3}$, respectively. As a conclution, the particle size was varies inversely with the density. As an addition, the crystallographic analysis showed that the particle size is inversely proportional to the Lc value.
\end{abstract}

Keywords: particle size, physical characteristic, activated carbon, flower of elephant grass

\section{Pendahuluan}

Elektroda karbon merupakan elektroda yang mempunyai struktur bahan berupa karbon aktif yaitu karbon yang mempunyai porositas tinggi dan luas permukaan (surface area) yang luas. Elektroda karbon berfungsi sebagai tempat penyimpanan energi pada superkapasitor. Elekroda karbon lebih diminati karena perpaduan sifat kimia dan fisika yang menguntungkan, yaitu luas permukaan yang tinggi, tahan terhadap karat, 
stabil terhadap suhu dan porositas yang besar sehingga mudah dalam mengadsorpsi ion. Luas permukaan yang tinggi menyebabkan mikropori meningkat (diameter $<2$ $\mathrm{nm}$ ) sehingga meningkatkan nilai kapasitansi spesifik pada superkapasitor [1].

Luas permukaan elektroda karbon mempengaruhi kemampuan menyimpan energi pada superkapasitor. Luas permukaan dapat dikaitkan dengan ukuran partikel. Ukuran partikel yang digunakan pada penelitian ini bervariasi yaitu $<38 \mu \mathrm{m}$ dilanjutkan penggiligan selama $20 \mathrm{jam},<38 \mu \mathrm{m}$ dan $39-52 \mu \mathrm{m}$ yang bertujuan untuk mendapatkan ukuran partikel yang ideal untuk dijadikan sebagai elektroda karbon serta menentukan pengaruh ukuran partikel terhadap sifat fisis elektroda karbon. Elektroda karbon terbuat dari bunga rumput gajah. Pemilihan bunga rumput gajah sebagai bahan dasar elektroda karbon karena bunga rumput gajah memiliki kandungan karbon sebesar 52\% [2], tidak hanya itu rumput gajah mempunyai kadar selulosa sebesar $25 \%-40 \%$, hemiselulosa $25 \%-50 \%$ serta lignin $10 \%-30 \%$ [3]. Semakin banyak kandungan selulosa, hemilulosa, dan lignin maka karbon aktif yang dihasilkan juga semakin baik [4].

Sifat fisis sangat berperan dalam menenentukan kinerja elektroda karbon dalam menyimpan energi. Pengukuran sifat fisis yang dilakukan meliputi pengukuran densitas dan analisa kristalografi yang bertujuan untuk mengetahui struktur kristal berdasarkan analisa pola difraksi seperti parameter kisi dengan memanfaatkan gelombang elektromagnetik sinar-X.

\section{Metode Penelitian}

\subsection{Pembuatan elektroda karbon}

Tahap awal penelitian ialah persiapan bunga rumput gajah. Bunga rumput gajah (BRG) dibersihkan lalu dikeringkan dengan menggunakan cahaya matahari kemudian ditimbang sebanyak $30 \mathrm{~g}$ dan diprakarbonisasi menggunakan oven pada suhu $250^{\circ} \mathrm{C}$. Tahap selanjutnya BRG digiling menggunakan hard grinder untuk mendapatkan ukuran dua kali lebih kecil dari ukuran semula, kemudian digiling menggunakan ball milling selama 20 jam dengan massa BRG adalah $30 \mathrm{~g}$ untuk mendapatkan sampel yang halus. BRG yang telah di ball milling menghasilkan serbuk dengan ukuran bervariasi. Serbuk kemudian diayak dengan tujuan untuk mendapatkan serbuk yang lebih halus dan homogen. Serbuk karbon selanjutnya diberi label SA, SB dan SC, dimana SA adalah sampel dengan ukuran partikel $<38 \mu \mathrm{m}$ dilanjutkan penggilingan selama 20 jam, SB adalah sampel dengan ukuran partikel $<38 \mu \mathrm{m}$ dan SC adalah sampel dengan ukuran partikel 39-52 $\mu \mathrm{m}$.

Semua variasi sampel kemudian diaktivasi kimia dengan aktivator $\mathrm{NaOH}$ pada konsentrasi $0,4 \mathrm{M}$, setelah diaktivasi kimia sampel dinetralkan lalu dikeringkan.
Sampel yang telah kering ditimbang dengan massa $0,7 \mathrm{~g}$ dan dicetak menggunakan hidraulic press pada tekanan 8 ton hingga berbentuk pelet. Tahap selanjutnya pengukuran densitas dengan cara mengukur massa, ketebalan dan diameter. Densitas dihitung sebanyak tiga kali yaitu sebelum karbonisasi, setelah karbonisasi dan setelah aktivasi fisika. Tahap selanjutnya pelet dikarbonisasi menggunakan furnace pada suhu $600^{\circ} \mathrm{C}$ dilingkungan gas $\mathrm{N}_{2}$, setelah dikarbonisasi pelet diaktivasi fisika pada suhu $850^{\circ} \mathrm{C}$ menggunakan gas $\mathrm{CO}_{2}$. Pelet yang sudah diaktivasi fisika kemudian dinetralkan dengan air suling hingga $\mathrm{pH} \quad 7$ lalu dikeringkan.

\subsection{Pengukuran Densitas}

Pengukuran densitas dapat dilakukan dengan mengukur diameter, tebal dan massa elektroda karbon. Densitas dapat dihitung dengan menggunakan persamaan:

$$
\rho=\frac{m}{V}
$$

$$
\begin{aligned}
\text { dimana: } & \mathrm{m}=\text { massa }(\mathrm{g}) \\
\mathrm{V} & =\text { volume total sampel }\left(\mathrm{cm}^{3}\right) \\
\rho & =\text { densitas pelet karbon }\left(\mathrm{g} / \mathrm{cm}^{3}\right)
\end{aligned}
$$

\subsection{Pengukuran Derajat Kristalografi}

Pengukuran derajat kristalografi digunakan untuk mengetahui parameter kisi, seperti jarak antar kisi, tinggi dan lebar lapisan kisi. Alat yang digunakan yaitu Difraktometer Sinar-X Siemens D5000 dengan sumber sinar Cu k- $\alpha$ dan panjang gelombang 1,5418 $\AA$. Sudut difraksi yang digunakan adalah sudut $2 \theta$ pada rentang sudut $0-60^{\circ}$. Analisa Difraksi Sinar-X (XRD) bekerja berdasarkan hukum Bragg dengan persamaan sebagai berikut:

$$
\mathrm{n} \lambda=2 \mathrm{~d} \sin \theta
$$

dimana: $\mathrm{n}=$ orde difraksi $(1,2,3 \ldots)$

$$
\begin{aligned}
& \lambda=\text { panjang gelombang sinar-X }(\AA) \\
& d=\text { jarak antara dua kisi }(\AA) \\
& \theta=\text { sudut hamburan }\left(^{\circ}\right)
\end{aligned}
$$

Setiap puncak pada pola XRD mewakili satu bidang kristal yang memiliki orientasi tertentu dalam tiga sumbu dimensi. Berdasarkan pola Difraksi Sinar-X dapat diketahui dimensi mikrokristalin yang meliputi tinggi lapisan mikrokristalin (Lc) dan lebar lapisan mikrokristalin (La) dengan menggunakan persamaan Debye-Scherrer [5]:

$$
\begin{aligned}
& \mathrm{Lc}=0,9 \lambda / \beta \cos \theta_{002} \\
& \mathrm{La}=1,84 \lambda / \beta \cos \theta_{100}
\end{aligned}
$$




$$
\text { dimana }: \begin{aligned}
\text { Lc } & =\text { tinggi lapisan } \operatorname{kisi}(\AA) \\
\text { La } & =\text { lebar lapisan kisi }(\AA) \\
\lambda & =\text { panjang gelombang }(\AA)
\end{aligned}
$$

\section{Hasil dan Pembahasan}

\subsection{Hasil Pengukuran Densitas}

Grafik hasil densitas rata-rata elektroda karbon dapat dilihat pada Gambar 1:

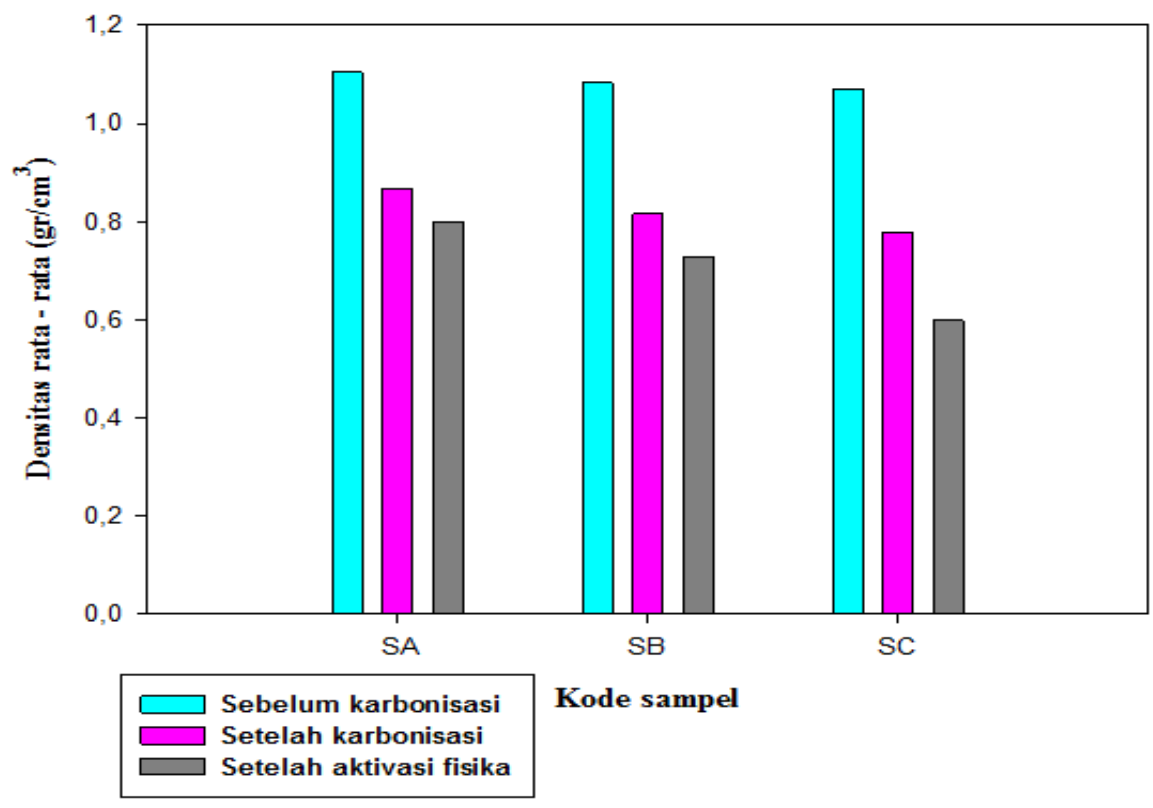

Gambar 1. Densitas rata-rata elektroda karbon

Gambar 1 menunjukan hubungan antara densitas rata-rata elektroda karbon untuk setiap jenis sampel. Densitas elektroda karbon dengan kode sampel SA, SB dan SC mengalami penurunan yang signifikan setelah karbonisasi. Penurunan terjadi karena pemanasan pada proses karbonisasi yang telah membuang bahan-bahan selain karbon seperti air dan gas yang terdapat pada sampel sehingga menyebabkan pengurangan massa dan densitas elektroda karbon. Densitas setelah aktivasi fisika mengalami sedikit penurunan karena perubahan massa elektroda hanya terjadi akibat hilangnya pengotor yang menutupi pori dan juga disebabkan oleh pemutusan rantai karbon untuk membentuk pori baru [6]. Densitas tertinggi terdapat pada sampel SA dan densitas terendah terdapat pada sampel SC. Densitas suatu elektroda dipengaruhi oleh ukuran suatu pertikel, jika ukuran partikel kecil maka elektroda yang terbentuk akan semakin padat, sedangkan jika ukuran partikel besar maka elektroda yang terbentuk akan semakin renggang sehingga berpengaruh pada massa dari elektroda. Gambar 1 juga menunjukkan bahwa nilai densitas berbanding terbalik dengan ukuran partikel. Densitas juga berpengaruh pada porositas suatu elektroda. Semakin rendah nilai densitas suatu elektroda maka akan semakin besar porositas yang terdapat pada elektroda.analisa densitas menunjukkan bahwa sampel SB memiliki porositas yang lebih besar. Porositas suatu elektroda akan mempengaruhi prestasi elektroda karbon dalam menyimpan energi.

\subsection{Hasil Pengukuran Derajat Kristalografi}

Kurva difraksi sinar-X elektroda karbon untuk masing-masing sampel dapat dilihat pada Gambar 2. Gambar 2 menunjukan data pengukuran XRD dari tiga variasi sampel yang menunjukkan keberadaan dua puncak pada sudut $2 \theta$ dalam rentang $10^{\circ}$ sampai $100^{\circ}$. Berdasarkan Gambar 2 terlihat bahwa kehadiran puncak amorf berada diantara sudut $2 \theta$ yaitu untuk sampel SA dan sampel SC sedangkan sampel SB memiliki dua puncak, yaitu amorf dan kristal. Bentuk amorf dari karbon dapat dilihat pada Gambar 2 untuk masingmasing elektroda yang ditandai oleh kurva dengan puncak yang landai dan sudut yang tumpul sedangkan puncak yang tajam yang terlihat pada sampel SB diindikasikan oleh kehadiran bahan silika $\left(\mathrm{SiO}_{2}\right)$ yang ditemukan pada partikel biomassa [7]. Puncak yang landai pada amorf disebabkan oleh struktur dari amorf yang tidak teratur sedangkan puncak yang tajam dari kristal disebabkan oleh struktur kristal yang teratur. Kehadiran puncak kristal biasanya disebabkan oleh proses pembuatan elektroda karbon dan pencucian yang kurang bersih. Puncak-puncak pada kurva mewakili orientasi bidang kristal dimana pada Gambar 2 dapat 


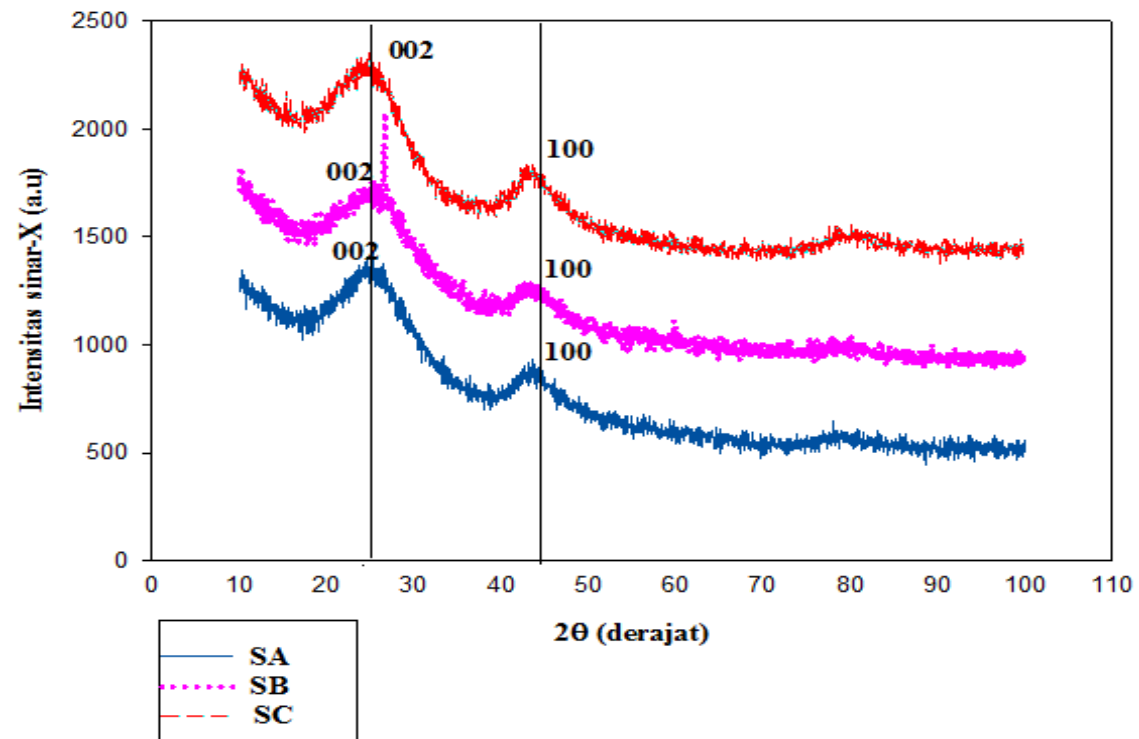

Gambar 2. Kurva XRD untuk masing-masing sampel

Hasil pengolahan data menggunakan software Microcal Origin 3.5 menunjukan besar sudut $2 \theta$ untuk puncak difraksi (002) dan (100), lebar puncak yang kemudian diolah untuk mengetahui $\mathrm{d}_{\mathrm{hkl}}$, La dan Lc dari struktur karbon. Hasil pengolahan data XRD dapat dilihat pada Tabel 1 .

Tabel 1. Data parameter kisi karbon aktif bunga rumput gajah

\begin{tabular}{|c|c|c|c|c|c|c|c|c|}
\hline No & $\begin{array}{c}\text { Kode } \\
\text { sampel }\end{array}$ & $\mathbf{2 \theta ( 0 0 2 )}$ & $\mathbf{2 \theta ( 1 0 0 )}$ & $\mathbf{d}(\mathbf{0 0 2})(\AA)$ & $\mathbf{d}(\mathbf{1 0 0})(\AA)$ & $\begin{array}{c}\text { Lc } \\
(\AA)\end{array}$ & $\begin{array}{c}\text { La } \\
(\AA)\end{array}$ & Lc/La \\
\hline 1 & SA & 25,381 & 45,388 & 3,506 & 1,996 & 11,985 & 13,499 & 0,888 \\
\hline 2 & SB & 25,707 & 44,457 & 3,463 & 2,037 & 11,602 & 14,972 & 0,775 \\
\hline 3 & SC & 24,818 & 44,649 & 3,584 & 2,028 & 11,241 & 19,829 & 0,567 \\
\hline
\end{tabular}

Unsur karbon umumnya terdeteksi pada sudut

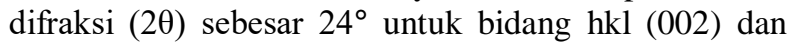
$44^{\circ}$ untuk bidang hkl (100). Berdasarkan data pada Tabel 1 sudut $2 \theta$ untuk sampel SA pada sudut $25,381^{\circ}$ dan $45,388^{\circ}$, sampel SB pada sudut $25,707^{\circ}$ dan $44,457^{\circ}$ dan sampel SC pada sudut $24,818^{\circ}$ dan $44,649^{\circ}$. Sudut-sudut tersebut menggambarkan posisi puncak yang sesuai dengan bidang (002) dan (001) pada struktur karbon [7]. Sudut $2 \theta$ dan nilai $\beta$ (width) yang dihasilkan dari fitting dapat menentukan nilai La dan Lc. Nilai Lc pada Tabel 1 dapat dijadikan rujukan untuk menganalisa luas permukaan sampel. Nilai La yang diperoleh pada elektroda SC lebih besar dari pada nilai La pada elektroda SA dan SB, sedangkan nilai Lc pada elektroda SC lebih kecil dari pada nilai Lc pada elektroda SA dan SB, ini menunjukkan bahwa Lc berbanding terbalik dengan La. Penurunan nilai Lc dipengaruhi oleh ukuran partikel yang digunakan, seiring meningkatnya ukuran partikel maka lebar timbunan mikrokristalin semakin besar sedangkan untuk tinggi timbunan mikrokristalin berkurang sehingga luas permukaan yang dihasilkan akan semakin besar hal ini didukung dengan teori yang menyatakan $\mathrm{S}=2 / \rho \mathrm{Lc}$ artinya nilai Lc yang kecil menghasilkan luas permukaan yang besar [8].

Berdasarkan analisa densitas dan sifat kritalinitas dapat dibuat suatu penegasan hubungan densitas, kristalinitas dengan luas permukaan. Analisa densitas menunjukan bahwa sampel SC mempunyai nilai densitas yang paling rendah, berarti sampel SC 
memiliki porositas terbesar dan diharapkan sampel ini mempunyai luas permukaan tinggi. Analisa kristalinitas menunjukan sampel SC mempunyai nilai Lc terkecil dan secara teori diprediksi sampel ini mempunyai luas permukaan terbesar. Akhirnya dapat dilihat hubungan yang konsisten antara densitas dan derajat kristalinitas

\section{Simpulan}

Pembuatan elektroda karbon dari bunga rumput gajah telah berhasil dilakukan dengan variasi ukuran partikel yang berbeda. Analisa densitas menyatakan bahwa sampel SC memiliki nilai densitas yang rendah ini berarti bahwa sampel SC memiliki porositas yang lebih tinggi. Pengukuran XRD menunjukan bahwa partikel elektroda karbon dari bunga rumput gajah bersifat amorf dengan sudut $2 \theta$ berada pada rentang $24,818^{\circ}-45,388^{\circ}$ yang menunjukan keberadaan puncak (002) dan (100). Analisa kritalinitas menunjukan bahwa sampel SC mempunyai nilai Lc yang kecil artinya sampel SC diharapkan memiliki nilai luas permukaaan yang besar sehingga sampel SC ideal untuk dijadikan elektroda pada sel superkapasitor.

\section{Ucapan Terimakasih}

Penulis mengucapkan mengucapkan terima kasih kepada penyokong dana penelitian yaitu Proyek HIKOM tahun 2016 yang diberikan kepada Peneliti utama Dr. Erman Taer, M.Si. yang menyatakan sampel SC mempunyai sifat pori terbaik. Sebagai penutup analisa ini, diharapkan sampel SC mempunyai sifat fisis terbaik yang mendukung sifat elektrokimia yang baik jika digunakan sebagai elektroda pada sel superkapasitor.

\section{Daftar Acuan}

[1] A. M.Namisnyk, A survey of electrochemical supercapacitrs technology, Faculty of Engineering, University of Technology, Sydney. (2003), pp. 12 -14 .

[2] E. Taer, H. Halim, R. Farma, R. Taslim, Karakterisasi partikel pra-karbon dari bunga rumput gajah (Pennisetum polystachyon) dengan campuran surfaktan anionik sodium dodesil sulfat sebagai bahan dasar superkapasitor. Prosiding Seminar Nasional Fisika UNJ IV (2015), pp. $67-$ 70.

[3] W. I. Lestari, pengambilan lignin dari batang rumput gajah dengan proses ekstraksi, Jurusan Teknik Kimia, Fakultas Teknologi Industri, Universitas Pembangunan Nasional "Veteran" Jawa Timur, (2012),p.2

[4] Y. Takeuchi, Pengantar Kimia. Tokyo, Iwanami Publishing Company (2006).

[5] B. D. Cullity, Elements of X-Rays Diffraction, Amazon, Prentice Hall (2001).

[6] H. Nurdiansah dan D. Susanti, Pengaruh variasi temperatur karbonisasi dan temperatur aktivasi fisika dari elektroda karbon aktif tempurung kelapa dan tempurung kluwak terhadap nilai kapasitansi electric double layer capacitor J. Teknik Pomits (EDLC) 2 (2013), pp. 13-18.

[7] E. Taer, M. Deraman, I. A. Thalib, A. Awitdrus, S. A. Hasmi, A. A. Umar, preparation of a highly porous binderless activated carbon monolith from rubber wood sawdust by a multi-step activation process for application in supercapacitors. Int. Journal Electrochem. Sci 6 (2011), pp. 3301 3315.

[8] K. Kumar, R.K. Saxena, R.D. Kothari, K. Suri, N.K. Kaushik, and J.N. Bohra, Correlation between adsorption and $\mathrm{X}$-ray diffraction studies on viscose rayon based activated carbon cloth, Carbon 35(12) (1997), pp. 1842-1844. 
